\title{
Role of hsa-miR-105 during the pathogenesis of paclitaxel resistance and its clinical implication in ovarian cancer
}

\author{
MAO LI ${ }^{1,2}$, SHUN ZHANG ${ }^{2}$, YUAN MA ${ }^{2}$, YANG YANG ${ }^{3}$ and RUIFANG AN ${ }^{1}$ \\ ${ }^{1}$ Department of Obstetrics and Gynecology, First Affiliated Hospital of Xi'an Jiaotong University, Xi'an, Shaanxi 710061; \\ ${ }^{2}$ Department of Obstetrics and Gynecology, Reproductive Medicine Center, Tangdu Hospital, \\ Air Force Military Medical University, Xi'an, Shaanxi 710038; ${ }^{3}$ Department of Obstetrics and Gynecology, \\ First Affiliated Hospital of Xi'an Medical University, Xi'an, Shaanxi 710082, P.R. China
}

Received August 5, 2020; Accepted January 21, 2021

DOI: $10.3892 /$ or.2021.8035

\begin{abstract}
More than $70 \%$ of patients with epithelial ovarian cancer (EOC), one of the leading cause of gynecological cancer-related deaths worldwide, are diagnosed at an advanced stage of the disease. Currently, the mainstay for treatment of advanced EOC is tumor debulking surgery followed by combined platinum- and paclitaxel (PTX)-based chemotherapy. However, most patients eventually develop chemoresistance, which remains a major obstacle to successful treatment. Herein, by using clinical specimens and experimentally induced cell models, we found that the expression levels of hsa-miR-105 were significantly decreased in PTX-resistant EOC tissues and cell lines. Follow-up functional experiments demonstrated that repression of hsa-miR-105 conferred resistance to paclitaxel in EOC cells, whereas restoration of hsa-miR-105 expression in situ via intratumoral injection of hsa-miR-105 micrON ${ }^{\text {тм }}$ agomir potentiated in vivo sensitivity to PTX and thereafter significantly inhibited tumor growth in a PTX-challenged xenograft model. Mechanistically, hsa-miR-105 exerted its tumor suppressor function by directly inhibiting the zinc and ring finger 2 (ZNRF2) signaling pathway. Importantly, aberrant expression of hsa-miR-105 in both tumor and circulating samples predicted a poor post-chemotherapy prognosis in EOC patients. These findings collectively suggest that hsa-miR-105 may act as a potent tumor suppressor miRNA during the progression of EOC, likely affecting cell proliferation, invasiveness and chemosensitivity to PTX, and functioning at least in part via inhibition of ZNRF2 signaling. The stability and availability and ease in measurement of circulating hsa-miR-105 make it a valuable diagnostic/prognostic biomarker candidate for chemotherapy of EOC.
\end{abstract}

Correspondence to: Dr Ruifang An, Department of Obstetrics and Gynecology, First Affiliated Hospital of Xi'an Jiaotong University, 277 Yanta West Road, Xi'an, Shaanxi 710061, P.R. China

E-mail: doctor_2020@126.com

Key words: ovarian cancer, paclitaxel resistance, hsa-miR-105, ZNRF2, circulating miRNA

\section{Introduction}

As one of the seventh most common types of cancer in women and the most lethal gynecologic cancer, ovarian cancer affects more than 295,000 females worldwide annually (1). Currently, epithelial ovarian cancer (EOC) is the major type of ovarian cancer (more than $90 \%$ of ovarian cancer cases are EOCs), and EOC has a higher prevalent rate compared to non-EOC (2). Based on statistical reports from 2008 to 2014 in the USA, the overall 5-year survival rate of EOC remains low at 29\% (3). This is largely due to the fact that EOC has few early symptoms and rapidly progress to an advanced stage (4). More than $70 \%$ of patients with EOC are diagnosed at an advanced stage of the disease (5). Additionally, molecular-targeted therapies (e.g. anti-PD-1/PD-L1 antibody and CAR-T) have not been demonstrated to be successful in EOC $(6,7)$. Innovative treatment with poly(ADP-ribose) polymerase-1 (PARP) inhibitors (PARPis) has demonstrated outstanding activity in EOC and can change clinical practice, but at present PARPis are mainly used in the treatment of BRCA-mutant patients (8). Currently, the mainstay for treatment of advanced EOC is tumor debulking surgery followed by a combination of platinum-based combination chemotherapy (usually for six cycles), with a platinum (carboplatin or cisplatin/CDDP) and a taxane (paclitaxel/PTX or docetaxel/DTX). Compared to other chemotherapeutic agents, PTX exhibits high tolerability, decreases hematological toxicities and neutropenia, thereby leading to an increase in the duration of the progression-free interval and overall survival (9). PTX is less myelosuppressive than DTX (10). PTX-CDDP chemotherapy has been shown to improve the complete and partial clinical response by 38.7 and $42.7 \%$, respectively. Thus, PTX-CDDP chemotherapy is now used as the first-line treatment for patients with advanced EOC (11). In spite of initial responsiveness, an estimated $85 \%$ patients, showing increased chemoresistance to the first-line chemotherapy agents, relapse within two years and ultimately die of recurrent disease (12). Second-line treatments can improve survival and quality of life but are not curative (13). Therefore, chemoresistance remains the main cause of treatment failure associated with advanced EOC (14), and there is an urgent need to elucidate the molecular mechanisms underlying chemoresistance to develop novel therapeutic targets. 
MicroRNAs (miRNAs), a cluster of 21-25 nt non-coding regulatory RNAs, regulate gene expression at the posttranscriptional level, inducing the degradation of target mRNAs or translational repression. Over $70 \%$ of all human genes are estimated to be regulated by miRNAs, indicating that gene regulation by miRNAs is likely involved in nearly every genetic pathway (15). In this regard, identification of the function of key miRNAs and a fuller understanding of their molecular bases should deepen insight into diverse biological processes and render novel clues to develop molecular targets for therapeutic intervention (16).

Compelling biochemical data suggest that dysregulation of miRNA expression is closely associated with response to chemotherapeutic agents, and alteration in the expression levels of miRNAs can cause substantial changes during oncogenesis (17). Hsa-miR-105 is such a striking example. The complex roles of miR-105 during cancer initiation and progression are gradually emerging. It can act as a tumor suppressor by inhibiting tumor growth and metastasis or as an oncogene by promoting tumor initiation and invasion, depending on the particular tumor context and base-pairing genes, in a variety of cancer types including colorectal cancer, hepatocellular carcinoma, breast cancer, lung cancer and glioma (18).

Interestingly, hsa-miR-105 can be secreted by solid tumors into circulation in which it further interacts with Agonature2 (Ago2) to increase stability. This makes hsa-miR-105 a valuable diagnostic/prognostic biomarker candidate because of its stability and availability and ease of measurement (19). In the present study, we sought to determine the expression profile of hsa-miR-105 in PTX-resistant EOC tissues and cell lines, and to uncover its role and corresponding molecular basis in the pathogenesis of paclitaxel resistance in EOC. Overall, our systematic analysis should pave the way for a better understanding of this unique miRNA in EOC.

\section{Materials and methods}

Data mining. A microRNA profiling microarray expression dataset consisting of three pairs of parental EOC cells and their PTX-resistant sublines (GSE148251) (20) was downloaded from Gene Expression Omnibus (GEO platform). The miRNA expression levels were analyzed using GEO2R bioconductor project and provided as $\log 2$ ratios (21). We explored three mRNA target-predicting algorithms including mirSVR, Target scan and miRDB to screen the potential downstream targets of hsa-miR-105 (22).

Cell treatment. The human EOC cell lines (SKOV3, TOV21G and OVCAR8) and 293T cells, obtained from the American Type Culture Collection (ATCC), were maintained in RPMI-1640 medium supplemented with $10 \%(\mathrm{v} / \mathrm{v})$ fetal bovine serum (FBS), penicillin $(100 \mathrm{U} / \mathrm{ml})$, streptomycin $(100 \mathrm{U} / \mathrm{ml})$ and amphotericin $\mathrm{B}(25 \mu \mathrm{g} / \mathrm{ml})$ at $37^{\circ} \mathrm{C}$ in a $5 \% \mathrm{CO}_{2}$ atmosphere. The PTX-resistant cell lines (SKOV3/PTX and TOV21G/PTX) were generated by exposing parental cells to gradually increased doses of PTX (Sigma-Aldrich; Merck $\mathrm{KGaA}$ ), and were finally maintained in complete medium containing $50 \mathrm{nM}$ PTX (23). All cell lines used were recently authenticated using short tandem repeat analysis performed by Suzhou Genetic Testing Biotechnology, and were tested for mycoplasma contamination using Universal Mycoplasma Detection Kit (ATCC) prior to the experiments.

Oligonucleotide transfection and lentiviral transduction. Hsa-miR-105 mimics and inhibitors for in vitro transfection and hsa-miR-105 micrON ${ }^{\mathrm{TM}}$ agomir for in vivo transfection, along with their negative controls, were purchased from Ribobio. Zinc And Ring Finger 2 (ZNRF2) lentiviral shRNA particle was obtained from GeneCopoeia. To manipulate the hsa-miR-105 expression, cells were transfected with $100 \mathrm{nM}$ mimics or inhibitors with the aid of Lipofectamine ${ }^{\mathrm{TM}} 3000$ (Thermo Fisher Scientific, Inc.) for 48 h. For lentiviral transduction, the viral particles were prepared by co-transfection of expression plasmid and packaging plasmids into 293T cells, followed by harvest of virus-containing supernatants $48 \mathrm{~h}$ after transfection. SKOV3 and TOV21G cells were then transduced with the lentivirus, followed by selection of positive clones using $1 \mu \mathrm{g} / \mathrm{ml}$ of puromycin (Sigma-Aldrich; Merck KGaA) for $\sim 14$ days.

Measurement of in vitro cytotoxicity. Forty-eight hours after transfection with the indicated oligonucleotides, EOC cells were seeded in 96 -well plates at the density of $5 \times 10^{3}$ cells/well. Cells were then exposed to different doses of PTX as indicated or DMSO for $24 \mathrm{~h}$ after adhering to the plate. Upon completion of PTX treatment, fresh medium was added and cell viability was determined using Cell Counting Kit-8 (MedChemExpress), as per the manufacturers' instructions. Each concentration was conducted in triplicate and repeated at least twice. The half maximal inhibitory concentration $\left(\mathrm{IC}_{50}\right)$ of cell viability was calculated as the level that caused 50\% reduction in cell viability vs. the parental cells (24).

Clonogenic assay. About 500 cells were seeded into the 6-well plates. After a 48-h culture, PTX $(20 \mathrm{nM})$ was added into the cultures. After a 3-day treatment with PTX, cells were transferred to fresh medium and cultured for another 12 days until colonies were large enough to be clearly discerned. Cells were then fixed using 4\% paraformaldehyde (Sigma-Aldrich; Merck KGaA) for $20 \mathrm{~min}$, followed by staining with crystal violet stain solution (0.5\%) (Sangon Biotech). Counting colonies was finally achieved by using Oracle Java SE software (25), with the average number of colonies being plotted (mean $\pm \mathrm{SD}, \mathrm{n}=3$ ).

Cell invasion assay. The invasiveness of EOC cells in PTX-containing medium was determined by Transwell chamber (26). Briefly, $1 \times 10^{5}$ cells were seeded in the upper chamber of a Transwell with Matrigel-coated membrane (Corning, Inc.). After a 24-h culture, cells were then treated with $20 \mathrm{nM}$ of PTX for another $24 \mathrm{~h}$, followed by removal of cells from the upper chamber. The cells that had migrated to the lower surface were fixed and stained with 4',6-diamidino-2-phenylindole (DAPI; Thermo Fisher Scientific, Inc.) for $5 \mathrm{~min}$ and then counted under a Leica M205 FCA fluorescence microscope (Leica Microsystems, Inc.). Ten randomly selected fields were chosen for cell number quantification.

In vivo inhibition of hsa-miR-105 and tumor xenograft assay. All animal research was conducted in accordance with Guide 
for the Care and Use of Laboratory Animals from NIH, and was approved by the Animal Research Ethics Board of First Affiliated Hospital of Xi'an Jiaotong University (approval no. XMU-2012-1682). Animals were maintained under a constant 12-h light:12-h darkness cycle (lights on at 08:00 h) and controlled conditions of humidity (between 70 and $80 \%)$ and temperature $\left(22 \pm 1^{\circ} \mathrm{C}\right)$. They were allowed free access to experimental diets and water, and were allowed to acclimatize for at least 1 week before the experiment. For establishment of the tumor xenograft model, $2 \times 10^{6} \mathrm{SKOV} 3 / \mathrm{PTX}$ or TOV21G/PTX cells were subcutaneously injected into flanks of female BALB/cA-nu mice $(n=125,6$-weeks-old, weighing 19-23 g, obtained from the Animal Facility of The First Affiliated Hospital of Xi'an Medical University). On day 13 post cell inoculation, mice received intraperitoneal injections of $5 \mathrm{mg} / \mathrm{kg}$ of PTX (dissolved in PBS) $/ \mathrm{kg}$ body weight every three days. On the following day of the first PTX injection, 10 nmol of hsa-miR-105 micrON ${ }^{\mathrm{TM}}$ agomir or negative control (dissolved in $0.1 \mathrm{ml}$ PBS) was locally injected into the tumor mass once every 3 days for two weeks. Mice receiving PBS injection served as the negative controls. The animals were checked daily, and tumor volume (V) was recorded and calculated using the formula: $V=\left(\right.$ length $\mathrm{x}$ width $\left.{ }^{2}\right) / 2$. Humane endpoints used in this study included tumor ulceration, infection, or necrosis, loss of ability to ambulate (inability to access food or water) and labored respiration. Four weeks after cell inoculation, mice were sacrificed by cervical dislocation following sodium pentobarbital anesthesia $(200 \mathrm{mg} / \mathrm{kg}$, intraperitoneally). Some xenograft tissues were snap frozen in liquid nitrogen, followed by being stored at $-80^{\circ} \mathrm{C}$. The other xenografts were immediately fixed in $10 \%$ formalin and processed for histological examination.

Clinical specimens. Upon receipt of the written informed consent, a total of 115 female patients with EOC and known clinical follow-up were recruited from the Department of Obstetrics and Gynecology, First Affiliated Hospital of Xi'an Medical University during August 2012 and June 2019. All patients with EOC underwent initial cytoreductive surgery followed by 6-8 cycles of standard paclitaxel-based chemotherapy (27). Patients with progressive disease during primary chemotherapy according to medical image analysis or with recurrent disease within 6 months of completing primary chemotherapy were termed PTX-resistant (28). Some tumor samples were snap frozen in liquid nitrogen, followed by being stored at $-80^{\circ} \mathrm{C}$ until use, whereas other tumor samples were fixed in $10 \%$ formalin and processed for histological examination. The protocols involved in the human study strictly conformed to the 2008 Revised Declaration of Helsinki, and were approved by the Ethics Committee of the First Affiliated Hospital of Xi'an Medical University (approval no. XMU-2012-1683).

Real-time RT-qPCR. Real-time RT-qPCR was carried out as described elsewhere $(29,30)$. Total RNA was isolated and purified using PureLink ${ }^{\mathrm{TM}}$ miRNA Isolation Kit (Thermo Fisher Scientific, Inc.). RT-qPCR analysis of miRNA expression was performed using Applied Biosystems TaqMan microRNA assay system (Applied Biosystems), with the aid of microRNAspecific primers (5'-AAAAGCUGGGUUGAGAGGGCGA-3') and TaqMan ${ }^{\mathrm{TM}}$ MicroRNA Reverse Transcription Kit (Thermo Fisher Scientific, Inc.). To quantify the expression levels of other target genes, $500 \mathrm{ng}$ of total RNA was used to synthesize the first strand cDNA using iScript ${ }^{\mathrm{TM}}$ cDNA Synthesis Kit (Bio-Rad Laboratories, Inc.). Subsequent qPCR was carried out on the Applied Biosystems ${ }^{\circledR} 7500$ Fast Real-Time PCR System. Relative expression levels of target miRNA and mRNAs were determined using the standard ${ }^{\Delta \Delta} \mathrm{Cq}$ method (31), with human U6 snRNA or 18S RNA serving as the internal controls (32). Primers used in the current study are listed in Table I.

Western blot analysis. Western blot analysis was conducted according to published protocols (33). Total protein was prepared using ReadyPrep ${ }^{\mathrm{TM}}$ Protein Extraction Kit (Bio-Rad Laboratories, Inc.). Protein samples $(\sim 30 \mu \mathrm{g})$ were separated on $10 \%$ SDS-PAGE and transferred to PDVF membranes (Millipore Corp.). After being blocked by 5\% nonfat dry milk in TBST, the membranes were incubated with primary antibodies (Table II) at $4^{\circ} \mathrm{C}$ overnight. Positive signals were developed using an EZ-ECL Chemiluminescence Detection kit (Biological Industries) on a GOBlot ${ }^{\mathrm{TM}}$ Western Blot Processor (Cytoskeleton) after incubation with proper secondary antibodies.

Morphological examination. Localization of hsa-miR-105 in EOC cells was revealed by RNA fluorescence in situ hybridization (FISH) using a locked nucleic acid (LNA) probe for human mature hsa-miR-105 (5'-UCAAAUGCUCAG ACUCCUGUGGU-3') and scramble miRNA control probe (5'-GTGTAACACGTCTATACGCCCA-3'; Exiqon), both of which were labeled with digoxigenin at the 5 'end with the aid of the DIG RNA Labeling Kit (Roche). EOC cells were fixed in $4 \%$ paraformaldehyde, followed by hybridization at $37^{\circ} \mathrm{C}$ overnight in a dark moist chamber. After thorough rinse, cells were incubated with TSA fluorescent signal reaction solution (PerkinElmer) at room temperature for $30 \mathrm{~min}$ and were then sealed using Fluoroshield ${ }^{\mathrm{TM}}$ with DAPI histology mounting medium (Sigma-Aldrich; Merck KGaA). Positive staining was observed under a Leica M205 FCA fluorescence microscope.

The distribution of hsa-miR-105 in EOC tissues was revealed using chromogenic in situ hybridization (CISH) (29). Briefly, after a routine deparaffinization and rehydration, $4 \%$ paraformaldehyde-fixed paraffin-embedded EOC tissue sections were treated with $10 \mu \mathrm{g} / \mathrm{ml}$ of Proteinase K (Sigma-Aldrich; Merck KGaA) to expose RNA. Sections were then incubated sequentially with hybridization buffer without probes at $21^{\circ} \mathrm{C}$ for $2 \mathrm{~h}$ and with hybridization buffer containing $40 \mathrm{nM}$ of the above-mentioned DIG-labeled LNA-modified probes overnight. After incubation with the blocking solution (PBST containing $2 \%$ goat serum and $2 \mathrm{mg} / \mathrm{ml}$ bovine albumin) for $1 \mathrm{~h}$, sections were treated with anti-digoxigenin-AP antibody (Sigma-Aldrich; Merck KGaA) at $4^{\circ} \mathrm{C}$ overnight, followed by signal development using the BCIP/NBT Substrate Kit (Vector Laboratories, Inc.) according to the manufacturer's instruction.

Localization of the zinc and ring finger (ZNRF2) protein in EOC tissues was detected using immunohistochemistry as described elsewhere (34). In brief, $4 \%$ paraformaldehyde-fixed paraffin-embedded EOC tissue sections were routinely deparaffinized and rehydrated, followed by antigen retrieval by incubating slides in $0.01 \%$ citrate acid in a heated water bath 
Table I. Primer sequences used for real-time PCR analysis.

\begin{tabular}{|c|c|}
\hline Gene & Primer sequence \\
\hline \multirow[t]{2}{*}{$18 S$} & F: CTCGCCGCGCTCTACCTACCTA \\
\hline & R: ATGAGCCATTCGCAGTTTCACTG \\
\hline \multirow[t]{2}{*}{$T J P 1$} & F: AGCCATTCCCGAAGGAGTTG \\
\hline & R: ATCACAGTGTGGTAAGCGCA \\
\hline \multirow[t]{2}{*}{ SEPT14 } & F: CTGTGCCTGACCCACAATGA \\
\hline & R: TGCTGCTATGCGTCAGACAT \\
\hline \multirow[t]{2}{*}{ TM9SF2 } & F: GCCTGAAGAGGCCAGTCAAT \\
\hline & R: AATTCATTCTCGGGGAGGGC \\
\hline \multirow[t]{2}{*}{ ANKRD44 } & F: CGGTGTTGTGACTGAAACCC \\
\hline & R: AGGTTCTCGGGTCAGATCCA \\
\hline \multirow[t]{2}{*}{ SNX4 } & F: AGTTTTCAGTGAATGGAGTGCC \\
\hline & R: ATGTTTCCTGCACACAGCCC \\
\hline \multirow[t]{2}{*}{ ZNRF2 } & F: AGCACGACTGCCTTGTCTAT \\
\hline & R: TTCTGGCTGAGTATGCCTGC \\
\hline \multirow[t]{2}{*}{ Clorf168 } & F: GGTTCGAGCACCTCAACTTC \\
\hline & R: CCCCTGATAGTGTGACCAGC \\
\hline \multirow[t]{2}{*}{ EIF4A2 } & F: TCCAATGAGACAGGGCACAC \\
\hline & R: ATGGCTGCCTCAGTCCTTTC \\
\hline \multirow[t]{2}{*}{ LMO7 } & F: AGAGAATCCACAAGGAATTGA \\
\hline & R: TAGGGACTGTCATTTGGCCC \\
\hline \multirow[t]{2}{*}{$M L F 1$} & F: GGCCCACTTAGAGCGAAACT \\
\hline & R: ATGAGAACCCCAGCCTTTGG \\
\hline \multirow[t]{2}{*}{ ZFPM2 } & F: ACCCGGAAGTGAGATGCAAG \\
\hline & R: TCTCTTGGTCTGGTATTCCATCA \\
\hline \multirow[t]{2}{*}{ YTHDF3 } & F: CACCATTTCTTGGAACCCCAC \\
\hline & R: TGCCCTTAAAGCTACACATACA \\
\hline \multirow[t]{2}{*}{$R A P G E F 2$} & F: GATGCGAAGGGATTGCCCC \\
\hline & R: CGTACAGGAGGTCAGTGGTG \\
\hline \multirow[t]{2}{*}{ F13A1 } & F: CAACAGCTTGGAGGAGGGAG \\
\hline & R: CCCTTTTTGCAGCAACCCAG \\
\hline \multirow[t]{2}{*}{$S L C 5 A 1$} & F: CCAGCTTTTGTCACAGGTGC \\
\hline & R: AAACCCTGCAGGACAGATGG \\
\hline \multirow[t]{2}{*}{$H N R N P K$} & F: CAAAGGCCCACGGAGTTCTA \\
\hline & R: TATTCGCACTCCСCCTACCT \\
\hline \multirow[t]{2}{*}{$L D L R A D 3$} & F: GGCGTCCCCCTACCCTGTCAT \\
\hline & R: TGCTGCACACGGCTCCTCAC \\
\hline
\end{tabular}

F, forward; $R$, reverse.

$\left(95^{\circ} \mathrm{C}\right)$ for $30 \mathrm{~min}$. After elimination of endogenous peroxides activity by treatment for $10 \mathrm{~min}$ with $0.3 \%$ hydrogen peroxide in methanol, the sections were incubated with the primary antibody (Table II) at $4^{\circ} \mathrm{C}$ overnight. Positive signals were finally developed with the aid of the VECTASTAIN ${ }^{\circledR}$ Elite $^{\circledR}$ ABC system (Vector Laboratories, Inc.) according to the protocol recommended by the manufacturer.

Luciferase reporter assay. The 3'UTR segment of human ZNRF2 was amplified from ovarian cell genomic DNA and cloned into psiCHECK-2 luciferase reporter vector using Not I/XhoI sites. Site-directed mutagenesis of the hsa-miR-105 binding site on the ZNRF2 3'UTR was achieved using QuikChange Site-Directed Mutagenesis Kit (Agilent Technologies, Inc.). Co-transfection of reporter plasmids and hsa-miR-105 mimics into 293T cells was carried out using Lipofectamine ${ }^{\mathrm{TM}}$ 3000. Forty-eight hours after transfection, relative luciferase activity was measured by the Dual-Luciferase Reporter Assay System (Promega Corp.).

Ago2-mediated RNA-immunoprecipitation. FLAG-Ago2 was a gift from Edward Chan (Addgene plasmid no. 21538; Addgene) (35). The FLAG-Ago2 construct and hsa-miR-105 mimics were con-transfected into $293 \mathrm{~T}$ cells for $48 \mathrm{~h}$ using Lipofectamine $^{\mathrm{TM}} 3000$, followed by cell harvest using RIPA buffer supplemented with RNase A, DNase and protease-free from Thermo Fisher Scientific, Inc. The FLAG ${ }^{\circledR}$ Tag antibody (Thermo Fisher Scientific, Inc.) was preincubated with Protein G-agarose beads (Sigma-Aldrich; Merck KGaA) at $4^{\circ} \mathrm{C}$ overnight. Subsequently, the resultant cell lysates were incubated with preconjugated antibody at $4^{\circ} \mathrm{C}$ overnight. Pellets from immunoprecipitation were then dissolved in TRIsure ${ }^{\mathrm{TM}}$ (BioLine) and subjected to PCR analysis.

Statistical analysis. All experiments were conducted in triplicate and repeated at least twice. Quantitative values are expressed as the mean \pm SD. Differences among/between experimental groups were analyzed by one-way analysis of variance (ANOVA) followed by Tukey's test or Student's t-test, wherever appropriate. The association between hsa-miR-105 expression and overall survival was assessed using the log-rank Kaplan-Meier analysis. The receiver operating characteristic (ROC) curve was used to examine the predictive power. $\mathrm{P}<0.05$ was considered to be statistically significant.

\section{Results}

Downregulation of hsa-miR-105 expression in paclitaxelresistant EOC cells. As an initial effort to understand the potential involvement of hsa-miR-105 in paclitaxel resistance, we examined the expression of hsa-miR-105 in a microRNA profiling microarray expression dataset consisting of three pairs of parental EOC cells and their PTX-resistant sublines (GSE148251) (20). Student's t-test demonstrated that the expression of hsa-miR-105 was significantly downregulated in PTX-resistant sublines compared to their parental cell lines (percentage decrease $>78.8 \%, \mathrm{P}<0.0001$, Fig. 1A). To validate these findings, we generated the PTX-resistant SKOV3/PTX and TOV21G/PTX cell lines using a previously validated protocol. SKOV3/PTX and TOV21G/PTX cells were -31.4 and -18.1 times more resistant to PTX than their parental SKOV3 and TOV21G cells, respectively (Fig. 1B). Compared to the expression level of hsa-miR-105 in the parental cells which was set at $100 \%$, the relative percentage of hsa-miR-105 expression in SKOV3/PTX and TOV21G/PTX cells was 34.2 and $28.6 \%$, respectively (Fig. 1C). Moreover, FISH analysis revealed a highly enriched expression of hsa-miR-105 in the parental SKOV3 cells compared to the PTX-resistant SKOV3/PTX subline (Fig. 1D). To further provide the in vivo evidence for the association between deregulated expression of hsa-miR-105 and paclitaxel resistance, we established a xenograft model to mimic the clinical treatment with PTX. At two weeks after PTX treatment, xenografts derived from 
Table II. Sources of antibodies and the working dilutions that were used for western blotting or immunostaining in the present study.

\begin{tabular}{|c|c|c|c|}
\hline Antibody & Vendor & Catalog no. & Dilutions \\
\hline Rabbit anti-Ki67 & Abcam & ab15580 & $1: 500(\mathrm{IHC})$ \\
\hline Rabbit anti-ZNRF2 & Thermo Fisher Scientific, Inc. & PA5-84890 & $1: 1,000$ (IB) $1: 150($ IHC) \\
\hline Rabbit anti-Flag & Sigma-Aldrich/Merck KGaA & F7425 & $1: 1,000(\mathrm{IB})$ \\
\hline Rabbit anti-ACTIN & Abcam & $\mathrm{ab} 8227$ & $1: 2,500(\mathrm{IB})$ \\
\hline VECTASTAIN ${ }^{\circledR}$ Elite $^{\circledR}$ ABC HRP Kit & Vector Laboratories, Inc. & PK-7200 & $1: 500(\mathrm{IHC})$ \\
\hline Goat anti-rabbit IgG-HRP secondary antibody & Abcam & ab97200 & $1: 10,000$ (IB) \\
\hline
\end{tabular}

IHC, immunohistochemistry/immunostaining; IB, western blotting/immunoblotting.
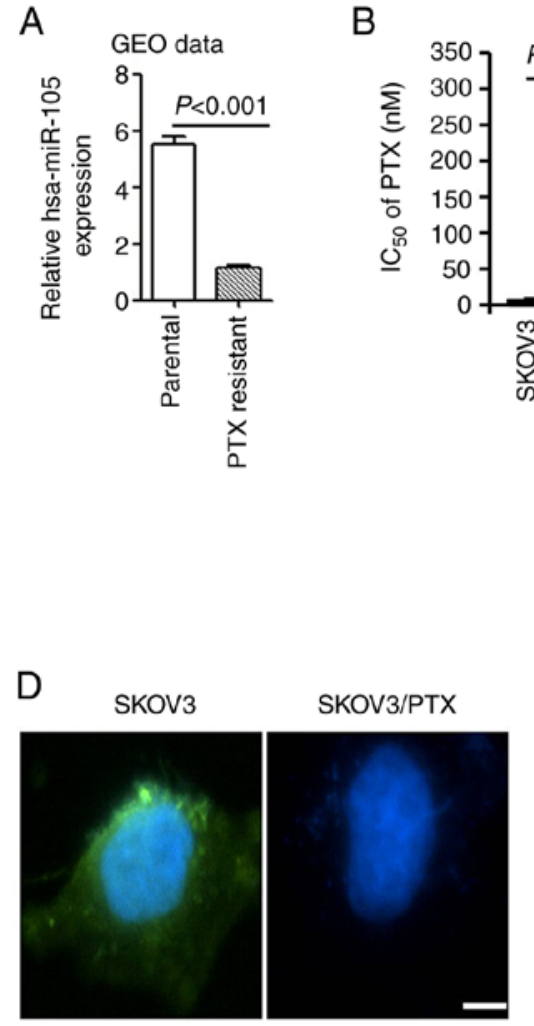

B

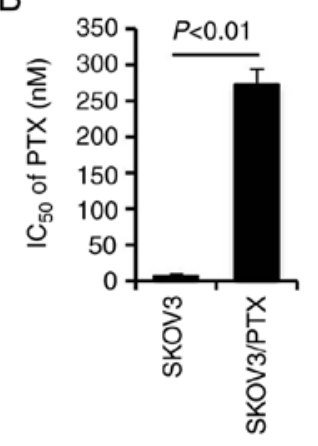

C

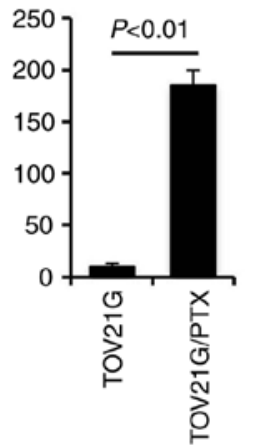

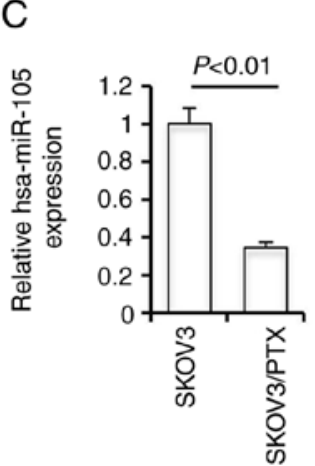

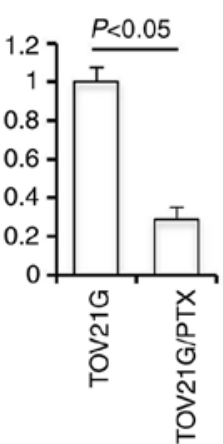

$\mathrm{E}$
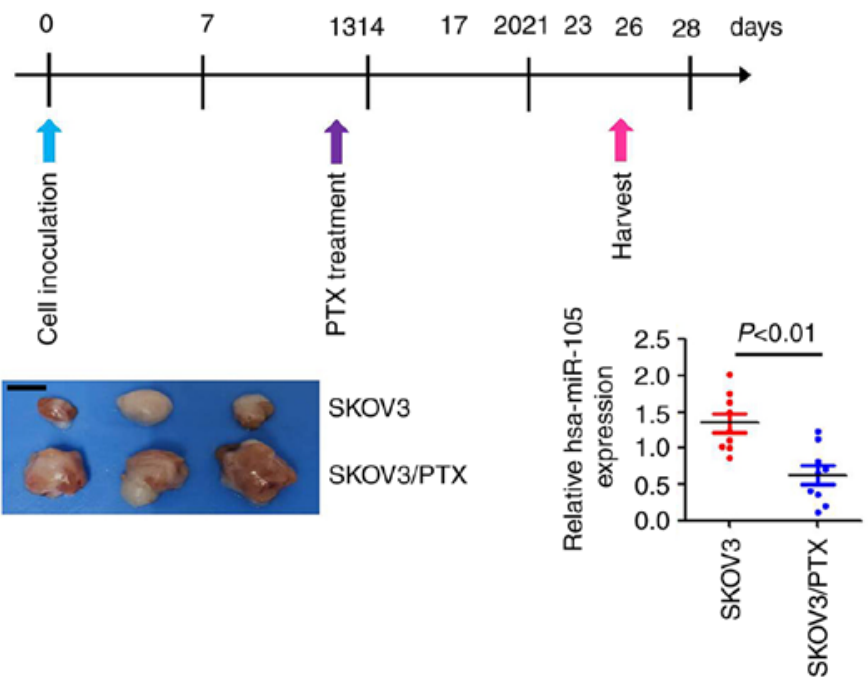

Figure 1. Downregulation of hsa-miR-105 in paclitaxel (PTX)-resistant epithelial ovarian cancer (EOC) cells. (A) Data analysis from GSE148251 (GEO dataset, including three pairs of parental EOC cells and their PTX-resistant sublines) demonstrated that hsa-miR-105 expression is significantly decreased in PTX-resistant EOC cells $(\mathrm{P}<0.001)$. (B) Determination of PTX $\mathrm{IC}_{50}$ in different cells using Cell Counting Kit-8 assay. (C) Real-time RT-qPCR analysis of hsa-miR-105 expression in different cells ( $\mathrm{n}=5$ ). (D) Localization of hsa-miR-105 in SKOV3 and SKOV3/PTX cells was revealed by RNA-FISH assay ( $\mathrm{n}=3$ ). Scale bar, $10 \mu \mathrm{m}$. (E) Real-time RT-qPCR analysis of hsa-miR-105 expression in a PTX-challenged xenograft model derived from SKOV3 and SKOV3/PTX cells. Upper panel: Protocols employed for the intraperitoneal (i.p.) injection of PTX in a xenograft model derived from SKOV3 and SKOV3/PTX cells. Lower left panel: Representative images of tumor sizes from the different groups at two weeks after PTX treatment. Lower right panel: RT-qPCR analysis of hsa-miR-105 expression in the xenografts $(\mathrm{n}=9)$. Scale bar, $5 \mathrm{~mm}$. $\mathrm{IC}_{50}$, half maximal inhibitory concentration.

SKOV3/PTX cells were clearly larger than those derived from parental SKOV3 cells, indicative of a successful resistance of SKOV3/PTX cells to PTX. Subsequent qPCR analysis showed that the expression of hsa-miR-105 in the SKOV3/PTX xenografts was significantly reduced by $\sim 53.6 \%$ compared to the SKOV3 xenografts $(\mathrm{P}<0.01$, Fig. 1E). These data together suggest that hsa-miR-105 deficiency correlates with paclitaxel resistance in EOC cells.

Inhibition of hsa-miR-105 confers paclitaxel resistance in EOC cells. To explore the oncogenic roles of the hsa-miR-105 deficiency, we silenced the expression of hsa-miR-105 


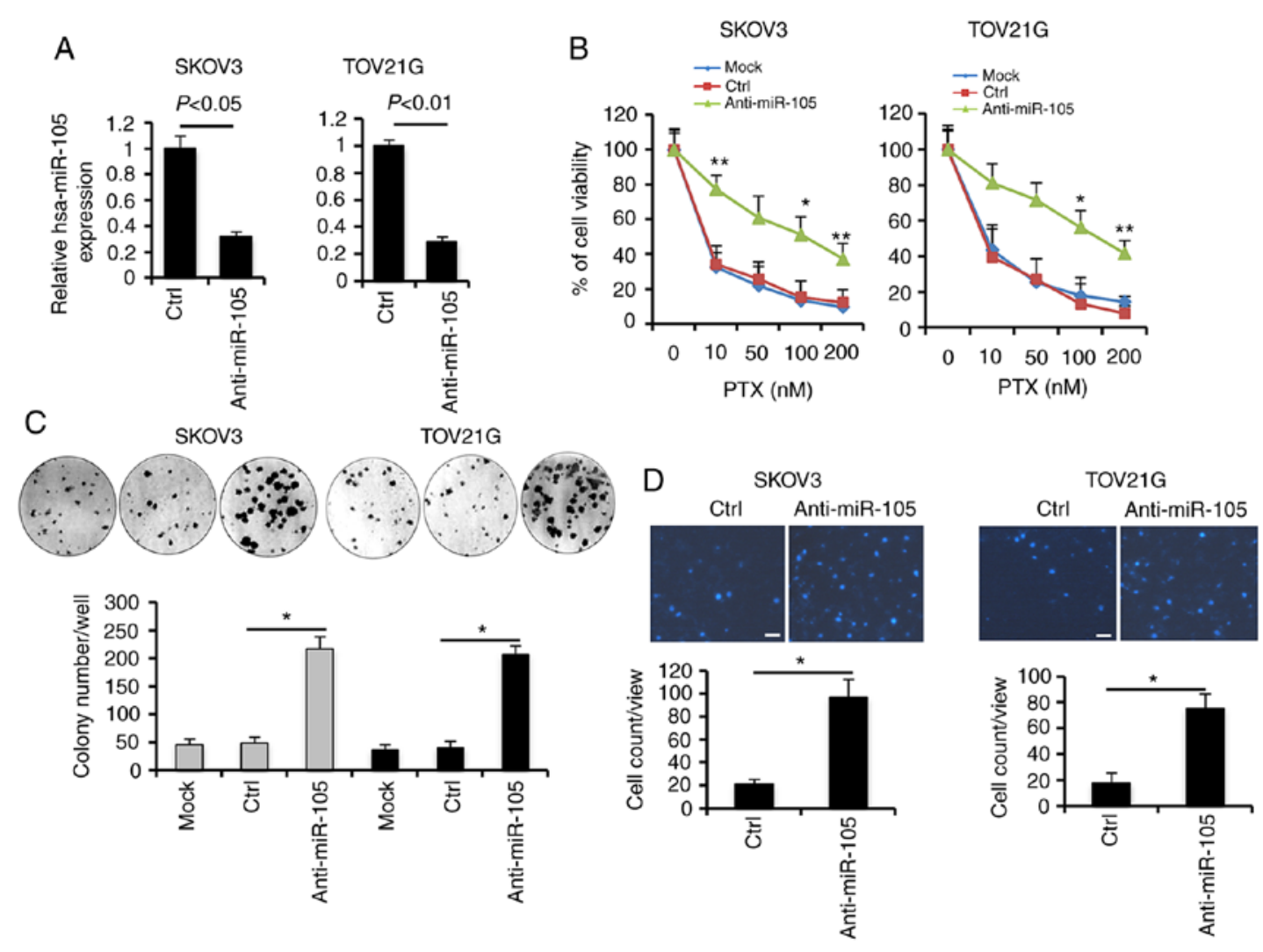

Figure 2. Inhibition of hsa-miR-105 attenuates chemosensitivity to paclitaxel (PTX) in epithelial ovarian cancer (EOC) cells. (A) SKOV3 and TOV21G cells were transfected with $100 \mathrm{nM}$ hsa-miR-105 inhibitors (anti-miR-150) or negative control using Lipofectamine ${ }^{\mathrm{TM}} 3000$. Following $48 \mathrm{~h}$, the cells were harvested and RT-qPCR analysis was carried out to determine the hsa-miR-105 levels. (B) Forty-eight hours after transfection with the indicated oligonucleotides, EOC cells were seeded in 96-well plates at the density of $5 \times 10^{3}$ cells/well. Cells were then exposed to different doses of PTX as indicated or DMSO for $24 \mathrm{~h}$, followed by measurement of cell viability using Cell Counting Kit-8 $\left({ }^{*} \mathrm{P}<0.05,{ }^{* *} \mathrm{P}<0.01\right)$. (C) Anchorage-dependent clonogenic ability of EOC cells with different transfections was assessed using colony formation assay ("P<0.05). (D) Effects of hsa-miR-105 inhibition on cell invasiveness were evaluated using a Transwell assay, as described in Materials and methods $(" \mathrm{P}<0.05)$. Scale bar, $10 \mu \mathrm{m}$.

in SKOV3 and TOV21G cells using specific inhibitors (anti-miR-105) (Fig. 2A). Following PTX treatment, knockdown of hsa-miR-105 expression conferred a stronger pro-survival effect in a dose-dependent manner, as revealed by viability assays (Fig. 2B). Consistently, higher efficiency of colony formation upon PTX co-incubation was observed in the hsa-miR-105 inhibitor (anti-miR-105)-transfected SKOV3 and TOV21G cells (Fig. 2C). Additionally, ablation of endogenous expression of hsa-miR-105 significantly increased cell invasiveness by $\sim 3.6$ - and $\sim 3.2$-fold in PTX-challenged SKOV3 and TOV21G cells, respectively (Fig. 2D). We also used another serous EOC cell line (OVCAR8) to elucidate the potential involvement of hsa-miR-105 in the development of resistance to PTX (Fig. S1). These findings suggest that hsa-miR-105 deficiency may confer resistance to paclitaxel in EOC cells.

Restoration of hsa-miR-105 expression in situ leads to dramatic inhibition of EOC growth. In order to investigate the antitumor effects of hsa-miR-105 at the in vivo level, we employed the micrON ${ }^{\mathrm{TM}}$ agomir system which has been shown to be promising for therapeutic gene delivery in vivo (36). We evaluated the therapeutic effects of micrON ${ }^{\mathrm{TM}}$ agomir-mediated hsa-miR-105 restoration on tumor growth in a xenograft model derived from either SKOV3/PTX or TOV21G/PTX cells (Fig. 3A). Intratumoral injection of hsa-miR-105 micrON ${ }^{\mathrm{TM}}$ agomir resulted in a significant increase in hsa-miR-105 expression in xenografts at 28 days after cell inoculation (Fig. 3B), as well as an inhibition of tumor growth, especially during the late phase of PTX treatment (Fig. 3C). In accordance, the hsa-miR-105-overexpressing and PTX-treated tumors were smaller at 28 days after cell inoculation (Fig. 3D), and expressed lower levels of Ki67 (a well-known proliferation marker for human tumor cells, Fig. 3E), compared to the Ctrl group. These results indicate that in vivo inhibition of hsa-miR-105 expression by using the micrON ${ }^{\mathrm{TM}}$ agomir may have the potential to be used as an alternative therapeutic option for EOC.

Identification of ZNRF2 as a direct target of hsa-miR-105 in $E O C$. To further dissect the molecular basis underlying the effects of hsa-miR-105 on PTX responsiveness, we explored three mRNAtarget-predicting algorithms including mirSVR, Target scan and miRDB (22). A total of 17 genes were identified to be potential downstream targets of hsa-miR-105, as these genes were observed to be overlapped in all three databases (Fig. 4A). We then evaluated the transcriptional expression levels of these 17 genes in four pair of PTX-responsive and PTX-resistant EOC tissues using RT-qPCR. ZNRF2 was the only candidate gene whose expression was found to be increased by more than 3-fold in the PTX-resistant tissues compared with the PTX-responsive EOC tissues (Fig. 4B). Transfection with hsa-miR-105 mimics caused a significant 

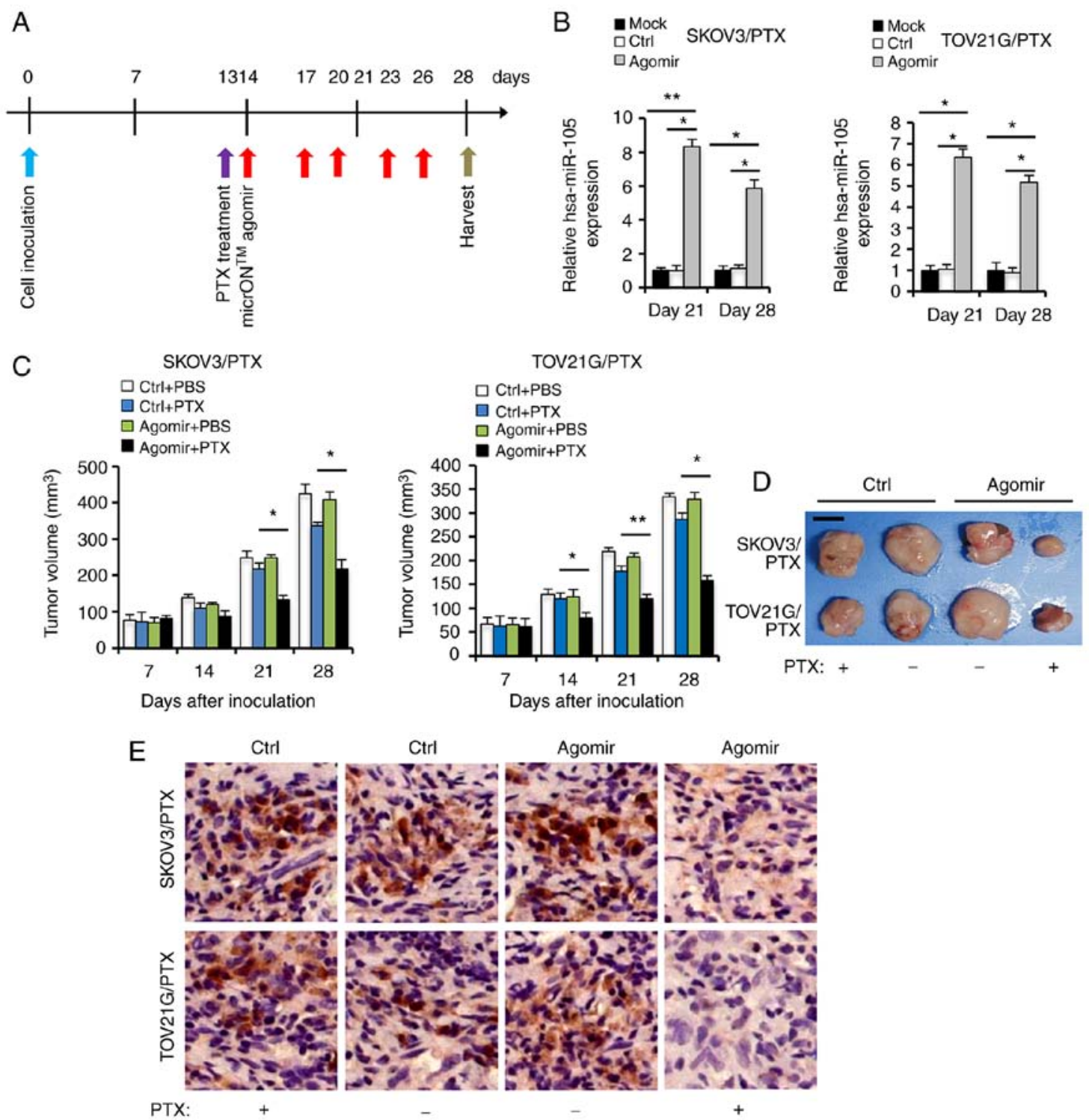

Figure 3. Replenishment of hsa-miR-105 expression via intratumoral injection of hsa-miR-105 micrON ${ }^{\mathrm{TM}}$ agomir potentiates in vivo sensitivity to paclitaxel (PTX). (A) Protocols employed for the intratumoral injection of hsa-miR-105 micrON ${ }^{\mathrm{TM}}$ agomir followed by PTX treatment in a xenograft model. (B) hsa-miR-105 levels in xenografts were determined using RT-qPCR at different time points after cell inoculation $\left({ }^{*} \mathrm{P}<0.05,{ }^{* *} \mathrm{P}<0.01\right)$. (C) SKOV3/PTX or TOV21G/PTX cells $\left(2 \times 10^{6}\right)$ were subcutaneously injected into flanks of female BALB/cA-nu mice. On Day 13 post cell inoculation, the mice received intraperitoneal (i.p.) injections of $5 \mathrm{mg} / \mathrm{kg}$ of PTX (dissolved in PBS) $/ \mathrm{kg}$ body weight every three days. On the following day of the first PTX injection, $10 \mathrm{nmol}$ of hsa-miR-105 micrON ${ }^{\mathrm{TM}}$ agomir or negative control (dissolved in $0.1 \mathrm{ml} \mathrm{PBS}$ ) was locally injected into the tumor mass once every 3 days for two weeks. Mice receiving PBS injection served as the negative controls. Tumor volumes are shown ("P $\left.<0.05,{ }^{* * *} \mathrm{P}<0.01\right)$. (D) Representative images of tumor sizes from the different groups at two weeks after PTX treatment. Scale bar, $5 \mathrm{~mm}$. (E) Representative images showing Ki67 immunohistochemical in xenografts derived from agomir-treated SKOV3/PTX or TOV21G/PTX cells. Scale bar, $20 \mu \mathrm{m}$.

decrease in the expression of ZNRF2 in SKOV3/PTX and TOV21G/PTX cells, at both mRNA (Fig. 4C) and protein levels (Fig. 4D). Consistently, immunostaining and ISH analyses revealed that the expression of hsa-miR-105 was negatively correlated to the expression of ZNRF2 protein in EOC specimens from our clinical cohort (Fig. 4E). To provide the direct evidence for the direct regulation of ZNRF2 expression by hsa-miR-105, we performed luciferase reporter assay. Co-transfection of reporter plasmids and hsa-miR-105 mimics into $293 \mathrm{~T}$ cells resulted in a $\sim 66.4 \%$ reduction in the transcriptional activity of ZNRF2 3'UTR, while this inhibitory effect was totally abolished when the binding site of hsa-miR-105 on the 3'UTR of ZNRF2 was mutated (Fig. 4F). To better confirm the interaction between hsa-miR-105 and
ZNRF2, we conducted Ago2-mediated RNA-IP assay. In the cells that were co-overexpressed with hsa-miR-105 and FLAG-Ago2, ZNRF2 mRNA was found to bind hsa-miR-105 (Fig. 4G). These results collectively suggest that hsa-miR-105 may regulate cellular responsiveness to PTX by directly targeting ZNRF2 in EOC cells.

Validation of the functional role of ZNRF2 in hsa-miR-105-mediated PTX resistance. Since ZNRF2 has been shown to be involved in chemoresistance (37), we next investigated the biological effects of the manipulation of ZNRF2 expression in hsa-miR-105-mediated chemoresistance by generating SKOV3 and TOV21G cells that were stably transfected with ZNRF2 shRNA. Transfection with 

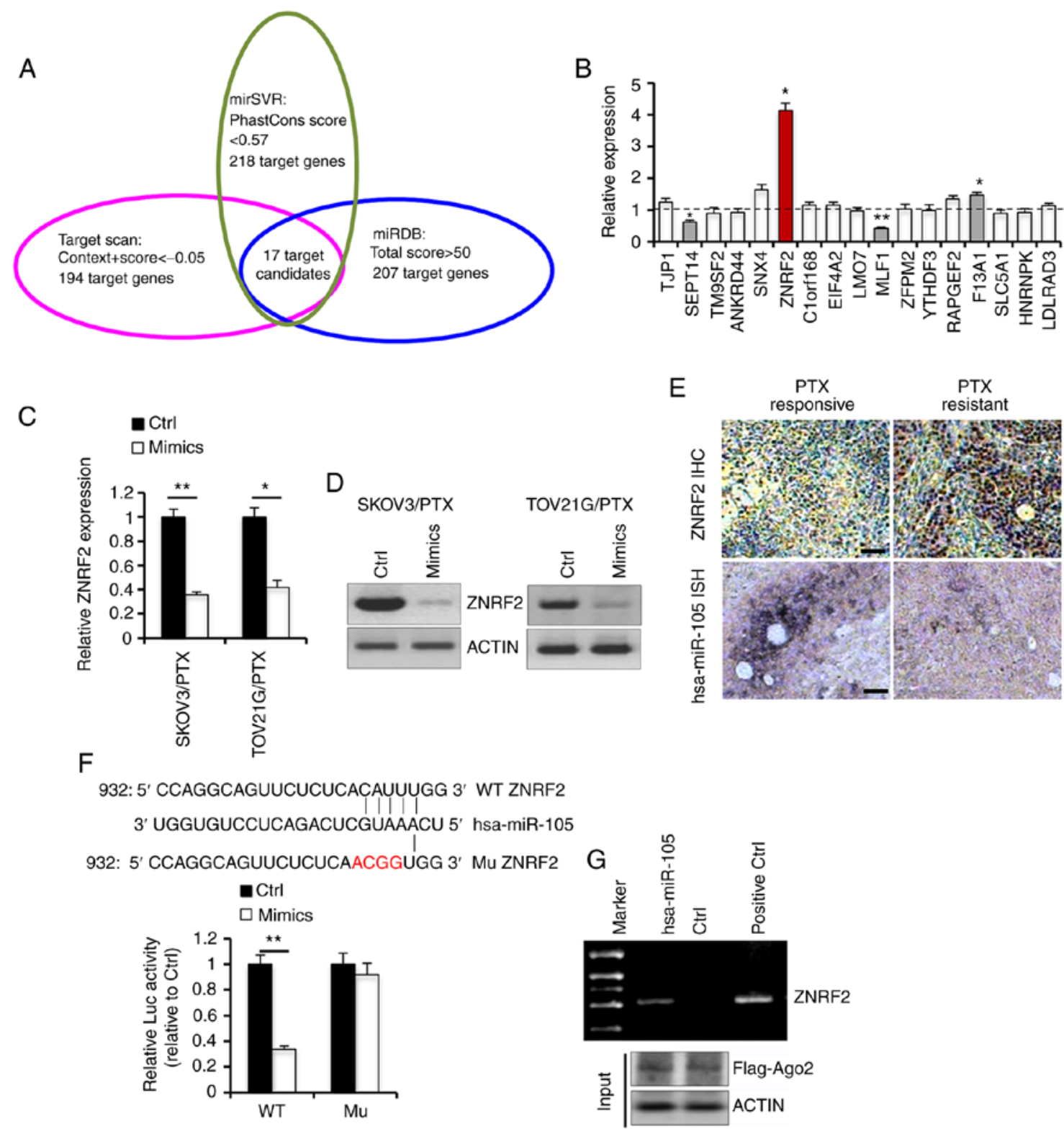

Figure 4. ZNRF2 functions as a direct target of hsa-miR-105 in epithelial ovarian cancer (EOC) cells. (A) Prediction of putative target genes of hsa-miR-105 by three online programs. (B) Transcriptional expression levels of 17 candidate genes in four pair of paclitaxel (PTX)-responsive and PTX-resistant EOC tissues were analyzed using real-time RT-qPCR ("P<0.05). (C and D) EOC cells were transfected with hsa-miR-105 mimics or Ctrl for $48 \mathrm{~h}$, followed by RT-qPCR ("P<0.05 and ${ }^{* *} \mathrm{P}<0.01$ when compared to NC) or western blot analysis. (E) Representative immunostaining of ZNRF2 and hsa-miR-105 ISH in PTX-responsive and PTX-resistant EOC tissues. Scale bar, $25 \mu \mathrm{m}$. (F) Luciferase reporter assay with co-transfection of wild-type (WT) or mutant (Mu) ZNRF2 and hsa-miR-105 mimics in 293T cells ( ${ }^{* *} \mathrm{P}<0.01$ when compared to Ctrl). (G) Ectopic overexpression of Flag-Ago2 with indicated miRNAs in 293T cells. Flag antibody was used to precipitate miRNA-Ago2-mRNA complex. The expression of ZNRF2 mRNA in complex with hsa-miR-105 was determined by PCR. ZNRF2, zinc and ring finger 2 .

hsa-miR-105 inhibitors (anti-miR-105) in control cells resulted in a significant increase in the expression level of ZNRF2, whereas this induction was totally abolished in the SKOV3 and TOV21G cells that were stably deprived of endogenous ZNRF2 (Fig. 5A). Hsa-miR-105 inhibition-induced cell survival upon PTX challenge was attenuated in the SKOV3 and TOV21G cells that were stably transfected with ZNRF2 shRNA (Fig. 5B). Furthermore, ZNRF2 depletion enhanced the ability of PTX to decrease colony formation efficiency (Fig. 5C), in the presence of hsa-miR-105 inhibition in both SKOV3 and TOV21G cells. Thus, we identified ZNRF2 as a main downstream effector mediating the action of hsa-miR-105 in the promotion of resistance to PTX.
Tumor and circulating hsa-miR-105 serves as a biomarker to predict PTX survival in EOC patients. In order to broaden the translational research enterprise of the current study, we measured the expression levels of hsa-miR-105 in tumor samples from a total of $115 \mathrm{EOC}$ patients that had received standard paclitaxel-based chemotherapy. The association between hsa-miR-105 expression and clinicopathological parameters of the patients with EOC is summarized in Table SI. Patients with high levels of hsa-miR-105 were more likely to have clinical response to PTX chemotherapy $(\mathrm{P}<0.0042)$. Tumor stage and grade did not significantly differ between patients with high levels of hsa-miR-105 and patients with low levels of hsa-miR-105 (Table SI). RT-qPCR revealed that hsa-miR-105 

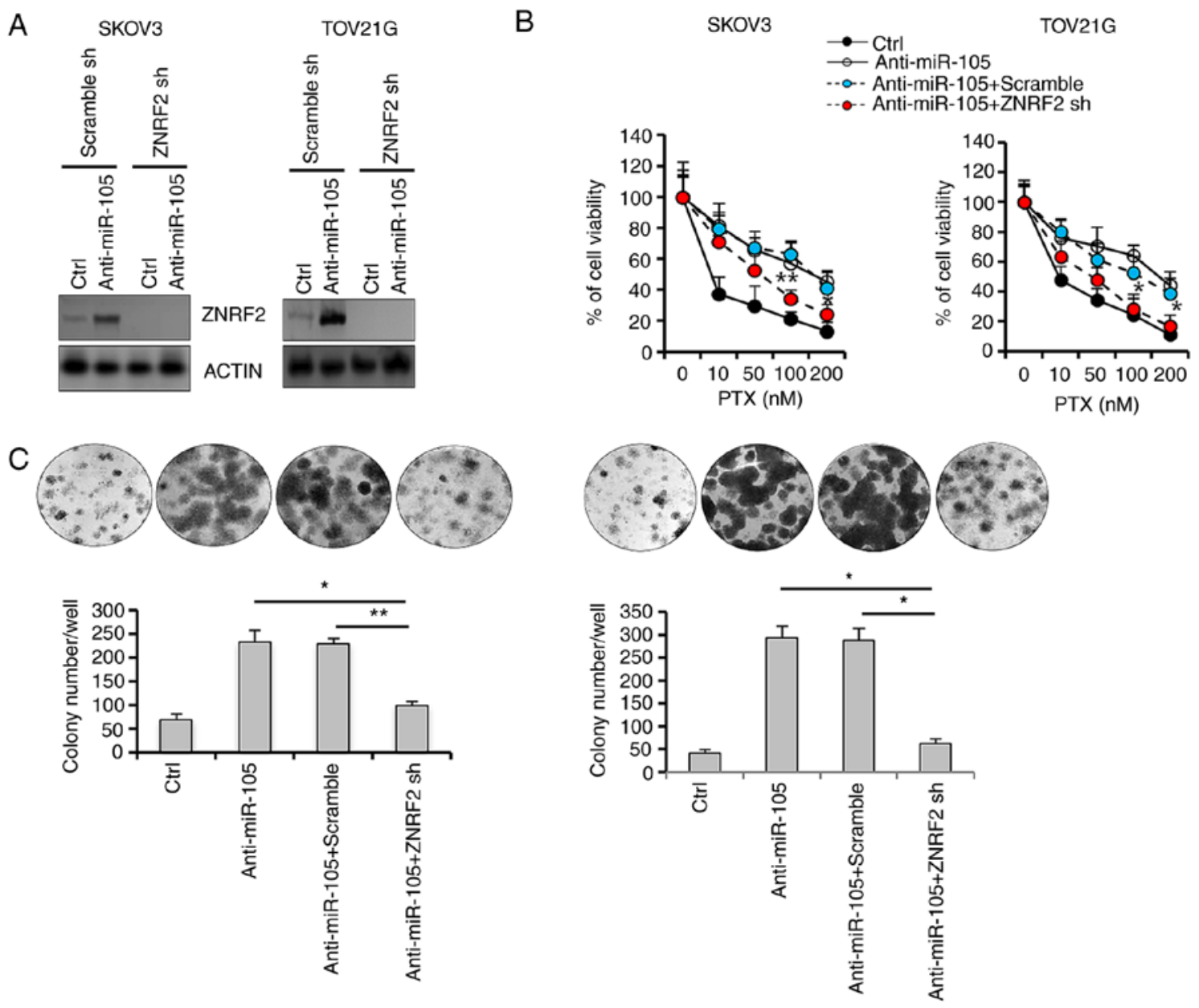

Figure 5. Stable knockdown of ZNRF2 potentiates paclitaxel (PTX) responsiveness in hsa-miR-105-delepted epithelial ovarian cancer (EOC) cells. (A) Establishment of EOC cells that were stably deprived of ZNRF2 expression was verified using western blot analysis. (B) Forty-eight hours after transfection with the indicated oligonucleotides, EOC cells were seeded in 96 -well plates at the density of $5 \times 10^{3}$ cells/well. Cells were then exposed to different doses of PTX as indicated or DMSO for $24 \mathrm{~h}$, followed by measurement of cell viability using Cell Counting Kit-8 ( $\left.{ }^{*} \mathrm{P}<0.05,{ }^{* *} \mathrm{P}<0.01\right)$. (C) Anchorage-dependent clonogenic ability of EOC cells with different transfections was assessed using colony formation assay ( $\left.\mathrm{P}<0.05,{ }^{* *} \mathrm{P}<0.01\right)$. ZNRF2, zinc and ring finger 2 .

was significantly downregulated in the PTX-resistant EOC specimens compared with that in the PTX-responsive EOC specimens $(\mathrm{P}<0.0001$, Fig. 6A). A ROC curve was then generated to assess the predictive power of hsa-miR-105. The corresponding AUC was 0.8649 (95\% CI, 0.8024-0.9275) (Fig. 6B), suggesting that hsa-miR-105 may serve as a valuable diagnostic biomarker for EOC chemotherapy. Importantly, the patients with lower levels of hsa-miR-105 exhibited poorer survival following PTX-based chemotherapy $(\mathrm{P}=0.0014$; Fig. 6C). Previous studies have identified hsa-miR-105 as a circulating miRNA (19). Given that circulating miRNAs are potent and convenient biomarkers for the evaluation of tumor development and progression (38), we sought to determine the clinical implication of hsa-miR-105 expression in the peripheral circulation using our 115-patient cohort. Expression levels of hsa-miR-105 were significantly decreased in the plasma of patients with PTX-resistant EOC, compared with those from patients with PTX-responsive EOC (P<0.0001; Fig. 6D). The contingency plot indicated that high levels of plasma hsa-miR-105 were associated with improved responsiveness to PTX (Fig. 6E). Subsequent ROC curve analysis revealed that the corresponding AUC was 0.8797 (95\% CI, 0.8169-0.9424) (Fig. 6F), verifying the predictive power of the circulating
hsa-miR-105. These clinical data support our pre-clinical findings and show that downregulation of hsa-miR-105 occurs in both tumor and peripheral circulation in the EOC patients with acquired PTX resistance.

\section{Discussion}

Hsa-miR-105 is located on human chromosome Xq28 (miRBase). Accumulated data suggest that hsa-miR-105 can play differential roles in various cancer types. For instance, hsa-miR-105 promotes the invasion and metastasis of colorectal cancer cells by directly targeting the RAP2C signaling (39). Likewise, hsa-miR-105 functions as an essential oncomiR in both non-small lung cancer (40) and breast cancer (41). By contrast, we demonstrated here that the expression of hsa-miR-105 was significantly downregulated in paclitaxel-resistant epithelial ovarian cancer (EOC) tissues and cell lines, and inhibition of the expression of hsa-miR-105 conferred paclitaxel resistance in EOC cells. Our findings are in accordance with previous reports that hsa-miR-105 exerts its anti-proliferative effects on gastric cancer (42) and inhibits cell aggressiveness in prostate cancer cells (43), thus indicating a tumor-suppressor role of this 
A

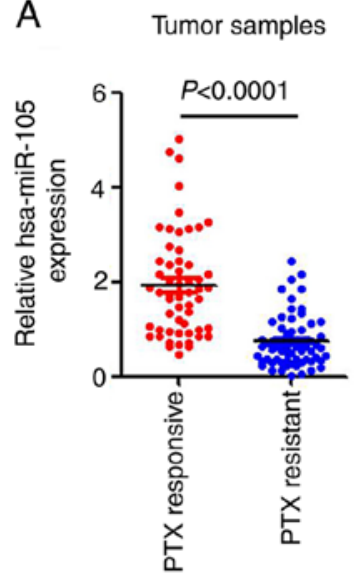

D

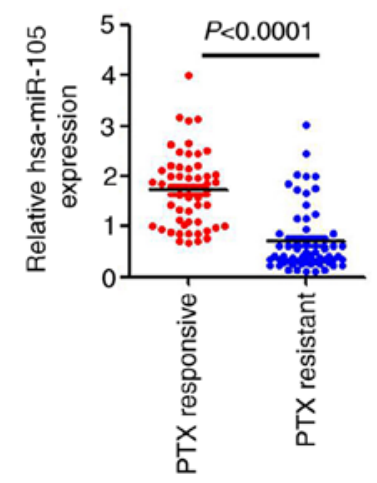

B

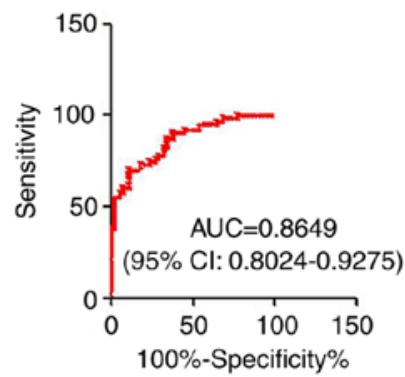

E

Plasma samples

- Low levels of hsa-miR-105

- High levels of hsa-miR-105

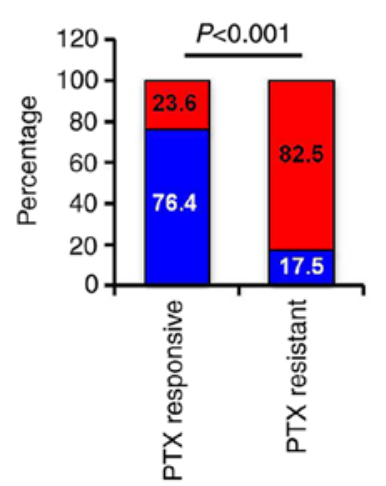

C Postoperative chemotherapy survival

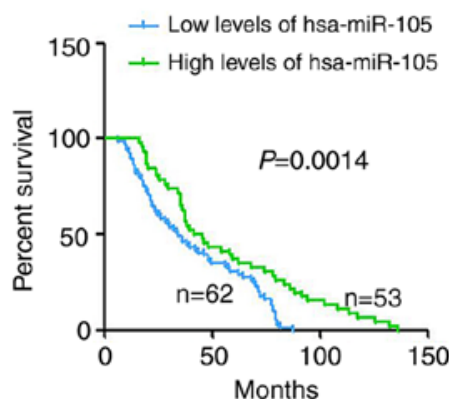

$\mathrm{F}$

Plasma samples

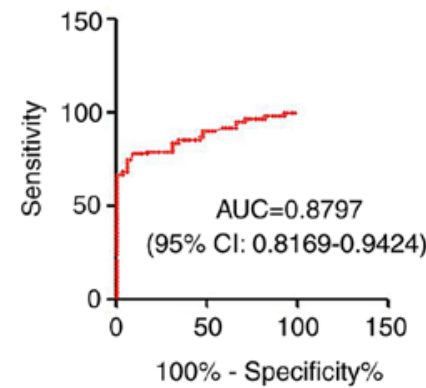

Figure 6. Tumor and circulating hsa-miR-105 acts as a predictive biomarker for paclitaxel (PTX) chemotherapy in epithelial ovarian cancer (EOC) patients. (A) hsa-miR-105 levels were measured in PTX-resistant EOC specimens ( $n=59)$ and PTX-responsive EOC specimens (n=56) using real-time RT-qPCR. (B) ROC curves were plotted to evaluate the predictive power of tumor hsa-miR-105 for the post-chemotherapy EOC patients. (C) Kaplan-Meier analysis of the association of hsa-miR-105 expression and overall survival of patients receiving PTX-based chemotherapy. (D) hsa-miR-105 levels were measured in serum samples from different patients using real-time RT-qPCR. (E) A contingency plot showing the distribution of PTX-responsive EOC and PTX-resistant EOC patients with the indicated circulating miRNA levels. The correlation was examined by Chi-square test. (F) ROC curves were plotted to evaluate the predictive power of circulating hsa-miR-105 for the post-chemotherapy EOC patients. ROC, receiver operating curve; AUC, area under the ROC curve; CI, confidence interval.

unique miRNA. Based on the available data, we reason that hsa-miR-105 may function as a double-faced gene expression regulator in cancer contexts, and whether it acts as an oncomiR or a tumor-suppressor miRNA is largely dependent on cancer type and cell context.

It is significant to know what causes the downregulation of hsa-miR-105 particularly in PTX-resistant EOC. Two possibilities are herein proposed. First, compelling data have suggested that epigenetic regulation functions as an essential mechanism modulating the expression of miRNAs $(44,45)$. In this regard, Zhou et al reported that hsa-miR-105 expression is decreased in gastric cancer cells, concomitantly with the DNA hypermethylation in the upstream region of the hsa-miR-105 promoter (42). Meanwhile, hypomethylation of CpGs in the promoter of hsa-miR-105 was found to activate the expression of the downstream CT-GABRA3 signaling pathway in melanoma cells (46). In the present study, treatment with a DNA methylation inhibitor RG108 partially restored the expression levels of hsa-miR-105 in PTX-resistant SKOV3/PTX or TOV21G/PTX cells (data not shown). Thus, deregulation of DNA hypermethylation in the hsa-miR-105 promoter may at least in part explain the reduced expression of hsa-miR-105 in PTX-resistant EOC cells. On the other hand, we cannot exclude the possibility that hsa-miR-105 expression is also subjected to a delicate control at the genetic level. In favor of this hypothesis, MYC and the core component of the $N F-\kappa B$ transcription complex (namely p65) are both proved to be crucial upstream regulators of hsa-miR-105 by directly targeting its chromatin $(47,48)$. Interestingly, by using bioinformatics, we observed that the hsa-miR-105 promoter contains a potential binding site of the MTA1 transcription factor. Given that there is an interactive feedback loop between MTA1 and the net transcription of the components of $\mathrm{NF}-\kappa \mathrm{B}$ pathway (49), it will be of future interest to investigate if a MTA1/hsa-miR-105 axis is also at play in drug resistance in EOC.

By using luciferase reporter assay, site-directed mutagenesis and Ago2-mediated RNA-immunoprecipitation, we further identify zinc and ring finger 2 (ZNRF2) as a direct target of hsa-miR-105 in EOC cells. ZNRF2 functions as a component of the amino acid sensing machinery that calibrates the cell's amino acid uptake, regulates proteasomal ubiquitin-dependent protein catabolic process, and governs 
cell fate (50). Recent advances in this field point out two characteristics regarding the roles of ZNRF2 in tumor biology. First, ZNRF2 is tightly associated with mammalian target of rapamycin (mTOR) signaling. ZNRF2 promotes amino acid-stimulated mTORC1 translocation to lysosomes to activate mTOR signaling (51). Given that mTORC1 and its downstream mRNA translation effectors protect cells against genotoxic DNA damage (52), it is therefore a logical observation that ZNRF2 is involved in the pathogenesis of paclitaxel resistance in EOC. Moreover, ZNRF2 expression is tightly regulated at the posttranscriptional level by miRNAs. For example, miR-100 suppresses human osteosarcoma cell proliferation and chemoresistance by directly targeting ZNRF2 (37). Similarly, miR-153-3p targets ZNRF2 to modulate tumorigenesis of papillary thyroid cancer (53). In our study, stable depletion of ZNRF2 expression enhanced the ability of PTX to decrease colony formation efficiency and to increase apoptosis in the presence of hsa-miR-105 inhibition in both SKOV3 and TOV21G cells. These findings lend functional support to the notion that ZNRF2 may serve as a main downstream target of hsa-miR-105 during the pathogenesis of paclitaxel resistance. Additionally, our in vivo assays have important therapeutic implications for EOC treatment, since restoration of the hsa-miR-105 expression in situ by intratumoral injection of micrON ${ }^{\mathrm{TM}}$ agomir significantly potentiated sensitivity to PTX and inhibited tumor growth. Thus, replenishment of hsa-miR-105 expression may contribute to chemotherapeutic sensitization as an alternative approach for EOC treatment.

The importance of the hsa-miR-105 pathway in the pathogenesis of chemoresistance in EOC was further attested by our in vitro studies, using combined paclitaxel and cisplatin treatment in SKOV3 and OVCAR8 cells that were deprived of hsa-miR-105 expression. Apparently, ablation of the endogenous hsa-miR-105 potentiated collateral resistance to cisplatin and paclitaxel in ovarian cancer cells (Fig. S2). In patients with cisplatin-resistant EOC, single chemotherapeutic agent (such as paclitaxel) has been shown to produce an objective response rate of less than $30 \%$. It is currently unclear how this collateral resistance occurs (54). To this end, our results suggest that acquired cisplatin resistance and acquired paclitaxel resistance may share a common pathogenic mechanism (e.g. regulation by miRNAs). Thus, further elucidating the molecular basis of hsa-miR-105 should provide valuable insights into therapeutic strategies for EOC patients.

Admittedly, a limitation of our study is that, due to the complex nature of this area, the exact mechanism underlying paclitaxel resistance cannot be elucidated by one single miRNA. Moreover, while our expression analyses focused on hsa-miR-105, we cannot rule out the potential involvement of additional miRNAs in the cancerous control of ZNRF2 expression, as our in silico analyses also highlighted other miRNAs with the ability to bind directly to the ZNRF2 gene. In this context, the future lines of research should be focused on investigating how differential miRNAs in EOC concordantly build regulatory networks that control different cellular responses to paclitaxel.

To summarize, in this study, we report that hsa-miR-105 expression levels were significantly decreased in PTX-resistant EOC tissues and cells. hsa-miR-105 regulates the chemosensitivity to PTX by directly targeting the ZNRF2 signaling pathway. Considering that hsa-miR-105 is a validated circulating miRNA (19), and that patients with lower levels of serum hsa-miR-105 tend to exhibit a poorer survival following PTX-based chemotherapy (present study), testing patients for hsa-miR-105 expression may provide more accurate prognostic information and could influence the recommended course of PTX treatment.

\section{Acknowledgements}

Not applicable.

\section{Funding}

The author(s) received no financial support for the research, authorship, and/or publication of this article.

\section{Availability of data and materials}

Data and materials are available upon reasonable request.

\section{Authors' contributions}

RA designed and supervised the experiments, and wrote the main manuscript text. ML performed the experiments and data analysis, and prepared the figures. SZ, YM, and YY provided administrative, technical, and material support. All authors read and approved the manuscript and agree to be accountable for all aspects of the research in ensuring that the accuracy or integrity of any part of the work are appropriately investigated and resolved.

\section{Ethics approval and consent to participate}

The protocols involved in the human study strictly conformed to the 2008 Revised Declaration of Helsinki, and were approved by the Ethics Committee of The First Affiliated Hospital of Xi'an Jiaotong University (approval no. XMU-2012-1683). All animal research was conducted in accordance with the Guide for the Care and Use of Laboratory Animals from the NIH, and was approved by the Animal Research Ethics Board of The First Affiliated Hospital of Xi'an Jiaotong University (approval no. XMU-2012-1682).

\section{Patient consent for publication}

Not applicable.

\section{Competing interests}

The authors declare that they have no competing interests.

\section{References}

1. Pokhriyal R, Hariprasad R, Kumar L and Hariprasad G: Chemotherapy resistance in advanced ovarian cancer patients. Biomark Cancer 11: 1179299X19860815, 2019.

2. Sawai T, Miyahara M, Nakajima H, Nakamori S, Sakai M, Tamada H, Tanigawa T, Yamada N, Nakamura M and Ito M: The impact of preprocedural hemoglobin A1c on the efficacy of sirolimus-eluting and paclitaxel-eluting stents. Cardiovasc Interv Ther 27: 72-83, 2012. 
3. Siegel RL, Miller KD and Jemal A: Cancer statistics, 2019. CA Cancer J Clin 69: 7-34, 2019.

4. Suh DH, Kim M, Lee KH, Eom KY, Kjeldsen MK, Mirza MR and Kim JW: Major clinical research advances in gynecologic cancer in 2017. J Gynecol Oncol 29: e31, 2018.

5. Winter WE III, Maxwell GL, Tian C, Carlson JW, Ozols RF, Rose PG, Markman M, Armstrong DK, Muggia F and McGuire WP; Gynecologic Oncology Group Study: Prognostic factors for stage III epithelial ovarian cancer: A gynecologic oncology group study. J Clin Oncol 25: 3621-3627, 2007.

6. Liu G, Zhang Q, Li D, Zhang L, Gu Z, Liu J, Liu G, Yang M, Gu J, Cui X, et al: PD-1 silencing improves anti-tumor activities of human mesothelin-targeted CAR T cells. Hum Immunol 82: $130-138,2021$.

7. Le Saux O, Dubois B, Stern MH, Terme M, Tartour E, Classe JM, Chopin N, Trédan O, Caux C and Ray-Coquard I: Current advances in immunotherapy in ovarian cancer. Bull Cancer 107: 465-473, 2020 (In French)

8. Cook SA and Tinker AV: PARP inhibitors and the evolving landscape of ovarian cancer management: A review. BioDrugs 33: 255-273, 2019

9. Naskou J, Beiter Y, van Rensburg R, Honisch E, Rudelius M, Schlensog M, Gottstein J, Walter L, Braicu EI, Sehouli J, et al: EZH2 loss drives resistance to carboplatin and paclitaxel in serous ovarian cancers expressing ATM. Mol Cancer Res 18: 278-286, 2020

10. Vasey PA, Paul J, Birt A, Junor EJ, Reed NS, Symonds RP, Atkinson R, Graham J, Crawford SM, Coleman R, et al: Docetaxel and cisplatin in combination as first-line chemotherapy for advanced epithelial ovarian cancer. Scottish gynaecological cancer trials group. J Clin Oncol 17: 2069-2080, 1999.

11. du Bois A, Luck HJ, Meier W, Adams HP, Möbus V, Costa S Bauknecht T, Richter B, Warm M, Schröder W, et al: A randomized clinical trial of cisplatin/paclitaxel versus carboplatin/paclitaxel as first-line treatment of ovarian cancer. J Natl Cancer Inst 95: 1320-1329, 2003.

12. Foley OW, Rauh-Hain JA and del Carmen MG: Recurrent epithelial ovarian cancer: An update on treatment. Oncology (Williston Park) 27: 288-294, 298, 2013

13. Hennessy BT, Coleman RL and Markman M: Ovarian cancer. Lancet 374: 1371-1382, 2009.

14. Zhang SF, Wang XY, Fu ZQ, Peng QH, Zhang JY, Ye F, Fu YF, Zhou CY, Lu WG, Cheng XD and Xie X: TXNDC17 promotes paclitaxel resistance via inducing autophagy in ovarian cancer Autophagy 11: 225-238, 2015.

15. Huh JH, Kim TH, Kim K, Song JA, Jung YJ, Jeong JY, Lee MJ, Kim YK, Lee DH and An HJ: Dysregulation of miR-106a and miR-591 confers paclitaxel resistance to ovarian cancer. $\mathrm{Br}$ J Cancer 109: 452-461, 2013.

16. Wei L, Sun J, Zhang N, Zheng Y, Wang X, Lv L, Liu J, Xu Y, Shen $\mathrm{Y}$ and Yang M: Noncoding RNAs in gastric cancer: Implications for drug resistance. Mol Cancer 19: 62, 2020.

17. Marengo B, Pulliero A, Izzotti A and Domenicotti C: MiRNA regulation of glutathione homeostasis in cancer initiation, progression and therapy resistance. Microrna 9: 187-197, 2020.

18. Li J, Zhang Z, Chen F, Hu T, Peng W, Gu Q and Sun Y: The diverse oncogenic and tumor suppressor roles of microRNA-105 in cancer. Front Oncol 9: 518, 2019.

19. Li HY, Liang JL, Kuo YL, Lee HH, Calkins MJ, Chang HT, Lin FC, Chen YC, Hsu TI, Hsiao M, et al: MiR-105/93-3p promotes chemoresistance and circulating miR-105/93-3p acts as a diagnostic biomarker for triple negative breast cancer. Breast Cancer Res 19: 133, 2017.

20. Kazmierczak D, Jopek K, Sterzynska K, Ginter-Matuszewska B Nowicki M, Rucinski M and Januchowski R: The significance of MicroRNAs expression in regulation of extracellular matrix and other drug resistant genes in drug resistant ovarian cancer cell lines. Int J Mol Sci 21: 2619, 2020.

21. Chai Y, Tan F, Ye S, Liu F and Fan Q: Identification of core genes and prediction of miRNAs associated with osteoporosis using a bioinformatics approach. Oncol Lett 17: 468-481, 2019.

22. Pla A, Zhong X and Rayner S: MiRAW: A deep learning-based approach to predict microRNA targets by analyzing whole microRNA transcripts. PLoS Comput Biol 14: e1006185, 2018.

23. Fu Y, Hu D, Qiu J, Xie X, Ye F and Lu WG: Overexpression of glycogen synthase kinase-3 in ovarian carcinoma cells with acquired paclitaxel resistance. Int J Gynecol Cancer 21: 439-444, 2011.

24. Sun NK, Huang SL, Chang TC and Chao CC: TLR4 and NFKB signaling is critical for taxol resistance in ovarian carcinoma cells. J Cell Physiol 233: 2489-2501, 2018.
25. Niyazi M, Niyazi I and Belka C: Counting colonies of clonogenic assays by using densitometric software. Radiat Oncol 2: 4, 2007.

26. Zhao G, Li Y and Wang T: Potentiation of docetaxel sensitivity by miR-638 via regulation of STARD10 pathway in human breast cancer cells. Biochem Biophys Res Commun 487: 255-261, 2017.

27. Fu Z, Wang C, Chen Y, Zhang X, Wang X and Xie X Down-regulation of UTP23 promotes paclitaxel resistance and predicts poorer prognosis in ovarian cancer. Pathol Res Pract 215 152625,2019

28. Li X, Lu Y, Chen Y, Lu W and Xie X: MicroRNA profile of paclitaxel-resistant serous ovarian carcinoma based on formalin-fixed paraffin-embedded samples. BMC Cancer 13: 216, 2013.

29. Zhang LL, Ma J, Yang B, Zhao J, Yan BY, Zhang YQ and Li W: Interference with lactate metabolism by mmu-miR-320-3p via negatively regulating GLUT3 signaling in mouse Sertoli cells. Cell Death Dis 9: 964, 2018.

30. Dong YS, Hou WG, Li Y, Liu DB, Hao GZ, Zhang HF, Li JC, Zhao J, Zhang S, Liang GB and Li W: Unexpected requirement for a binding partner of the syntaxin family in phagocytosis by murine testicular Sertoli cells. Cell Death Differ 23: 787-800, 2016.

31. Livak KJ and Schmittgen TD: Analysis of relative gene expression data using real-time quantitative PCR and the 2(-Delta Delta C(T)) method. Methods 25: 402-408, 2001

32. He K, Qu H, Wang H, Zhang S, Qian XH and Li W: Regulated and functional expression of the corepressor MTA3 in rodent testis. Endocrinology 157: 4400-4410, 2016.

33. Zhang C, Lai JH, Hu B, Zhang S, Zhao J and Li W: A chromatin modifier regulates Sertoli cell response to mono-(2-ethylhexyl) phthalate (MEHP) via tissue inhibitor of metalloproteinase 2 (TIMP2) signaling. Biochim Biophys Acta 1839: 1170-1182, 2014

34. Zhang S, Li W, Zhu C, Wang X, Li Z, Zhang J, Zhao J, Hu J, Li T and Zhang Y: Sertoli cell-specific expression of metastasis-associated protein 2 (MTA2) is required for transcriptional regulation of the follicle-stimulating hormone receptor (FSHR) gene during spermatogenesis. J Biol Chem 287: 40471-40483, 2012.

35. Lian SL, Li S, Abadal GX, Pauley BA, Fritzler MJ and Chan EK: The C-terminal half of human Ago2 binds to multiple GW-rich regions of GW182 and requires GW182 to mediate silencing. RNA 15: 804-813, 2009 .

36. Hou J, Lin L, Zhou W, Wang Z, Ding G, Dong Q, Qin L, Wu X, Zheng Y, Yang Y, et al: Identification of miRNomes in human liver and hepatocellular carcinoma reveals miR-199a/b-3p as therapeutic target for hepatocellular carcinoma. Cancer Cell 19: 232-243, 2011.

37. Xiao Q, Yang Y, An Q and Qi Y: MicroRNA-100 suppresses human osteosarcoma cell proliferation and chemo-resistance via ZNRF2. Oncotarget 8: 34678-34686, 2017.

38. Wang L and Zhang L: Circulating exosomal miRNA as diagnostic biomarkers of neurodegenerative diseases. Front Mol Neurosci 13: 53, 2020

39. Shen Z, Zhou R, Liu C, Wang Y, Zhan W, Shao Z, Liu J, Zhang F, $\mathrm{Xu} \mathrm{L}, \mathrm{Zhou} \mathrm{X}$, et al: MicroRNA-105 is involved in TNF- $\alpha$-related tumor microenvironment enhanced colorectal cancer progression. Cell Death Dis 8: 3213, 2017.

40. Jin X, Yu Y, Zou Q, Wang M, Cui Y, Xie J and Wang Z: MicroRNA-105 promotes epithelial-mesenchymal transition of nonsmall lung cancer cells through upregulating Mcl-1. J Cell Biochem 120: 5880-5888, 2019.

41. Zhou W, Fong MY, Min Y, Somlo G, Liu L, Palomares MR, Yu Y Chow A, O'Connor ST, Chin AR, et al: Cancer-secreted miR-105 destroys vascular endothelial barriers to promote metastasis. Cancer Cell 25: 501-515, 2014.

42. Zhou GQ, Han F, Shi ZL, Yu L, Li XF, Yu C, Shen CL, Wan DW, Zhu XG, Li R and He SB: DNMT3A-mediated down-regulation of microRNA-105 promotes gastric cancer cell proliferation. Eur Rev Med Pharmacol Sci 21: 3377-3383, 2017.

43. Honeywell DR, Cabrita MA, Zhao H, Dimitroulakos J and Addison CL: MiR-105 inhibits prostate tumour growth by suppressing CDK6 levels. PLoS One 8: e70515, 2013.

44. Cheng FHC, Lin HY, Hwang TW, Chen YC, Huang RL, Chang CB, Yang W, Lin RI, Lin CW, Chen GCW, et al: E2F6 functions as a competing endogenous RNA, and transcriptional repressor, to promote ovarian cancer stemness. Cancer Sci 110: 1085-1095, 2019

45. Braga EA,Loginov VI,Filippova EA,Burdennyi AM, Pronina IV, Kazubskaya TP, Khodyrev DS, Utkin DO, Kushlinskii DN, Adamyan LV and Kuslinskii NE: Diagnostic value of a group of MicroRNA genes hypermethylated in ovarian carcinoma. Bull Exp Biol Med 166: 253-256, 2018 
46. Loriot A, Van Tongelen A, Blanco J, Klaessens S, Cannuyer J, van Baren N, Decottignies A and De Smet C: A novel cancer-germline transcript carrying pro-metastatic miR-105 and TET-targeting miR-767 induced by DNA hypomethylation in tumors. Epigenetics 9: 1163-1171, 2014.

47. Yan W, Wu X, Zhou W, Fong MY, Cao M, Liu J, Liu X, Chen CH, Fadare O, Pizzo DP, et al: Cancer-cell-secreted exosomal miR-105 promotes tumour growth through the MYC-dependent metabolic reprogramming of stromal cells. Nat Cell Biol 20: 597-609, 2018.

48. Ji Q, Xu X, Xu Y, Fan Z, Kang L, Li L, Liang Y, Guo J, Hong T, Li Z, et al: MiR-105/Runx2 axis mediates FGF2-induced ADAMTS expression in osteoarthritis cartilage. J Mol Med (Berl) 94: 681-694, 2016.

49. Bui-Nguyen TM, Pakala SB, Sirigiri RD, Xia W, Hung MC, Sarin SK, Kumar V, Slagle BL and Kumar R: NF-kappaB signaling mediates the induction of MTA1 by hepatitis B virus transactivator protein HBx. Oncogene 29: 1179-1189, 2010.

50. Hoxhaj G, Caddye E, Najafov A, Houde VP, Johnson C, Dissanayake K, Toth R, Campbell DG, Prescott AR and MacKintosh C: The E3 ubiquitin ligase ZNRF2 is a substrate of mTORC1 and regulates its activation by amino acids. Elife 5: e12278, 2016.
51. Yang M, Zhai Z, Zhang Y and Wang Y: Clinical significance and oncogene function of long noncoding RNA HAGLROS overexpression in ovarian cancer. Arch Gynecol Obstet 300: 703-710, 2019.

52. Musa F, Alard A, David-West G, Curtin JP, Blank SV and Schneider RJ: Dual mTORC1/2 inhibition as a novel strategy for the resensitization and treatment of platinum-resistant ovarian cancer. Mol Cancer Ther 15: 1557-1567, 2016.

53. Cui Z, Luo Z, Lin Z, Shi L, Hong Y and Yan C: Long non-coding RNA TTN-AS1 facilitates tumorigenesis of papillary thyroid cancer through modulating the miR-153-3p/ZNRF2 axis. J Gene Med 21: e3083, 2019.

54. Ribeiro JR, Schorl C, Yano N, Romano N, Kim KK, Singh RK and Moore RG: HE4 promotes collateral resistance to cisplatin and paclitaxel in ovarian cancer cells. J Ovarian Res 9: 28, 2016.

(i)(9) This work is licensed under a Creative Commons Attribution-NonCommercial-NoDerivatives 4.0 International (CC BY-NC-ND 4.0) License. 